\title{
Preparation of human single-chain variable fragment antibodies against anaplastic thyroid carcinoma, and single photon emission-computed tomography/computed tomography imaging in tumor-bearing nude mice
}

\author{
QIAN LIU, HUA PANG, QIONG LIU, JING ZHOU and YING LIU \\ Department of Nuclear Medicine, The First Affiliated Hospital of Chongqing Medical University, \\ Chongqing 400016, P.R. China
}

Received November 7, 2016; Accepted December 7, 2016

DOI: $10.3892 /$ or.2017.5550

\begin{abstract}
Anaplastic thyroid carcinoma (ATC) is the most aggressive malignant thyroid tumor with the worst prognosis, and the response to treatment is poor. We investigated soluble human single-chain variable fragment $(\mathrm{scFv})$ which provides unique information for diagnostics, and for monitoring and optimizing responses to therapy. Enzyme-linked immunosorbent assay (ELISA) was used to detect the expression of scFv. The expression and relative molecular mass of soluble scFv were assessed by sodium dodecyl sulfate-polyacrylamide gel electrophoresis (SDS-PAGE) and western blotting, respectively. The chloramine $\mathrm{T}$ method was used to label scFv with ${ }^{131} \mathrm{I}$. The labeling rate and the radiochemical purity were determined. To analyze the distribution of ${ }^{131} \mathrm{I}-\mathrm{scFv}$ in body tissues and organs of nude mice, static single photon emission-computed tomography (SPECT) imaging and single photon emission-computed tomography/computed tomography (SPECT/CT) image fusion were performed. The relative molecular mass of soluble scFv was $\sim 29 \mathrm{kDa}$. The labeling rate was $91.64 \%$ and the radiochemical purity was $93.3 \pm 0.32 \%$. SPECT imaging revealed that ${ }^{131} \mathrm{I}-\mathrm{scF}$ v selectively accumulated in tumor tissue. In addition, SPECT/CT image fusion results were in agreement with the biodistribution results. In conclusion, the human $\mathrm{scFv}$ antibodies against ATC were successfully generated, and clear imaging of ${ }^{131} \mathrm{I}-\mathrm{scFv}$ in a nude mouse model at $48 \mathrm{~h}$ was obtained.
\end{abstract}

\section{Introduction}

Anaplastic thyroid carcinoma (ATC) is the most malignant form of thyroid cancer with the worst prognosis. However,

Correspondence to: Professor Hua Pang, Department of Nuclear Medicine, The First Affiliated Hospital of Chongqing Medical University, Chongqing 400016, P.R. China

E-mail:phua1973@163.com

Key words: anaplastic thyroid carcinoma, ${ }^{131} \mathrm{I}-\mathrm{scFv}$, preparation, radioimmunoimaging, SPECT/CT its incidence is at $\sim 7-8 \%$ (1). ATC undergoes early blood and lymphatic metastasis to distant tissues, showing characteristics of rapid progression, poor response to treatment and poor prognosis. The current treatment of ATC is controversial, and there is a lack of systematic treatment. At present, clinical treatment of ATC includes surgery, chemotherapy and radiotherapy, but the three methods only control the disease at the tumor site; the possibility of a radical cure is very low. For ATC patients, the average survival time is 3-10 months, the 1-year survival rate is at $\sim 20 \%$, and the 5-year survival rate is only $5-15 \%$ (2-5). Various studies have suggested the use of ${ }^{131} \mathrm{I}$ to treat ATC, but the degree of differentiation of ATC is low or it may be undifferentiated, thus, iodine may not be accumulated, losing the benefit of treatment. In recent years, various studies have made great progress in the study of antibodies. Luo et al used antibody phage display technology to construct an adenocarcinoma lung cancer phage antibody library, and then, used inoculation of human lung adenocarcinoma cells into nude mice in vivo and analyzed the biodistribution by carrying out further imaging (6). In addition, Qiong et al (7) completed phage antibody screening of human medullary thyroid carcinoma, and successfully used this technique for an imaging study, obtaining good results. With the maturation of phage display technology and its application, this technique provides a new method for the treatment of ATC.

Radioimmunoimaging (RII) is a method of imaging in vitro using a specific antibody conjugated to a radioactive isotope to make a drug-free conjugate. Its advantage is the use of the principle of specific binding of antigen and antibody, combined with imaging examination methods. The early location and qualitative diagnosis of a tumor is very important (8). To date, many researchers have tested RII using radio-pharmaceuticals combined with a corresponding antibody against tumor markers, and achieved marked results, such as those reported by Zhao et al (9) who used phage antibody display technology to construct an anti-ABCG2 single-chain variable fragment (scFv) antibody against lung adenocarcinoma, and then inoculated human lung adenocarcinoma cells into nude mice, and carried out further imaging to confirm specific binding.

In the present study, based on the findings of $\mathrm{Xi}$ et al (10), we completed the creation of an ATC human phage 
single-chain variable fragment antibody ( $\mathrm{scFv}$ ) library and successfully screened specific scFv of ATC, completed preparation and identification of ATC $\mathrm{scFv}$, and carried out RII using ${ }^{131} \mathrm{I}$-labeled $\mathrm{scFv}$ against ATC in tumor-bearing nude mice.

\section{Materials and methods}

General procedures. All cell lines were cultured in RPMI-1640 medium supplemented with $10 \%$ fetal bovine serum (both from Gibco, Thermo Fisher Scientific, Waltham, MA, USA) and 1\% penicillin/streptomycin under a humidified atmosphere of 5\% $\mathrm{CO}_{2}$ at $37^{\circ} \mathrm{C}$. Cells in the logarithmic phase of growth were used for all experiments.

All experiments using laboratory animals were carried out in accordance with the National Institutes of Health Guide for the Care and Use of Laboratory Animals (NIH Publications no. 8023, revised 1978).

The Symbia T2 single photon emission-computed tomography/computed tomography (SPECT/CT) detector was obtained from Siemens (Erlangen, Germany).

Production and purification of $s c F v$. A few phage clones that reacted with ARO cells detected from positive phage culture were used to infect $E$. coli HB2151 and inoculated onto a SOBAG culture plate and kept at $37^{\circ} \mathrm{C}$ overnight. The cells were then transferred to $2 \mathrm{X}$ YT-AI medium containing isopropyl- $\beta$-D-thiogalactoside (IPTG) and collected using centrifugation at shock times of 4 and $6 \mathrm{~h}$. Subsequently, the cells were resuspended in phosphate-buffered saline (PBS) and frozen at $-20^{\circ} \mathrm{C}$, then, subjected to five rounds of rapid thawing at $37^{\circ} \mathrm{C}$ followed by re-freezing. The bacteria were then subjected to ultrasonic disruption, and the supernatant containing the soluble scFv antibodies was collected and stored at $-20^{\circ} \mathrm{C}$. The soluble scFv was purified using a HiTrap ${ }^{\mathrm{TM}}$ Anti E-tag column. Each tube was monitored at an absorbance of $280 \mathrm{~nm}$, and the highest peak was identified as the purified soluble scFv antibody, which was stored at $4^{\circ} \mathrm{C}$.

Sodium dodecyl sulfate polyacrylamide gel electrophoresis (SDS-PAGE) and western blotting. To examine the expression of $\mathrm{scFv}$, the supernatants containing $\mathrm{ScFv}$ induced by IPTG in $E$. coli HB2151 at 4 and 6 h were run on SDS-PAGE followed by Coomassie brilliant blue staining, with uninduced E. coli HB2151 as the control group. Purified scFv was identified by western blotting.

Enzyme-linked immunosorbent assay (ELISA) detection of phage antibody. The TT, ARO and HepG 2 cells were cultured in 96 -well plates at $37^{\circ} \mathrm{C}$ for $48 \mathrm{~h}$, washed three times with PBS, and fixed with $2.5 \%$ glutaraldehyde. After fixation the cells were blocked for $1 \mathrm{~h}$ in $2 \%$ skim milk powder, subsequently they were washed in PBS and then again in PBS with Tween-20 (PBST). The purified scFv was added to the wells of a 96-well plate, then, HRP/anti m13k07 was added and the plate was incubated at $37^{\circ} \mathrm{C}$. PBS was used in place of purified $\mathrm{scFv}$ in ARO cells as the negative control group. 3,3',5,5'-Tetramethylbenzidine (TMB) dihydrochloride was added and allowed to react in the dark for $30 \mathrm{~min}$, then the absorbance was read at $450 \mathrm{~nm}$.
Radiolabeling, purification and radiochemical purity test. The scFv was labeled with ${ }^{131}$ I using the chloramine T method. An aliquot of $\mathrm{scFv}(250 \mu \mathrm{l})$ was mixed with $100 \mu \mathrm{l}{ }^{131} \mathrm{I}(50 \mathrm{mCi} / \mathrm{ml})$ for $3 \mathrm{~min}$. Then, $250 \mu \mathrm{l}$ chloramine $\mathrm{T}(1 \mathrm{mg} / \mathrm{ml})$ was added, and $1 \mathrm{~min}$ later $500 \mu \mathrm{l}$ sodium metabisulfite $(2 \mathrm{mg} / \mathrm{ml})$ was added, followed by $100 \mu \mathrm{l}$ of $1 \%$ potassium iodide to terminate the labeling process. The ${ }^{131} \mathrm{I}$-labeled $\mathrm{scFv}$ was purified by gel-filtration on a Sephadex G25M column. The chlorine-acetic acid method was used to assess the ${ }^{131} \mathrm{I}-\mathrm{scFv}$ labeling rate. The paper precipitation method was used to analyze ${ }^{131} \mathrm{I}-\mathrm{scFv}$ radiochemical purity, and to calculate the specific activity. Purified ${ }^{131} \mathrm{I}-\mathrm{scFv}$ was maintained at room temperature for 1 , 6,12 or $24 \mathrm{~h}$ and was then added into fresh human serum and incubated at $37^{\circ} \mathrm{C}$ for $1,6,12$ or $24 \mathrm{~h}$. Radiation was detected and the stability of the labeled conjugate at room temperature was analyzed.

Animal models and biodistribution. ARO cells were inoculated subcutaneously into the right forelimb of 4- to 6-week-old male nude mice (Department of Laboratory Animal Center at Chongqing Medical University). When the tumor volume reached $>1 \mathrm{~cm}^{3}$, mice were injected via the tail vein with $100 \mu \mathrm{l}$ of purified ${ }^{131} \mathrm{I}$-labeled scFv $(500 \mu \mathrm{Ci} / \mathrm{ml}, 18.5 \mathrm{MBq} / \mathrm{ml})$. Three mice were sacrificed at $12,24,48$ and $72 \mathrm{~h}$ after injection. The tumor, liver, kidney, spleen, heart, lung, stomach, intestine, brain, muscle and blood were removed from each mouse and weighed, and the radioactivity was determined using a $\gamma$ counter.

SPECT/CT and RII in tumor-bearing nude mice. The tumor-bearing mice were provided with water containing $1 \%$ potassium iodide for 3 days prior to imaging to block the thyroid, and were then injected with ${ }^{131} \mathrm{I}$-labeled $\mathrm{scFv}$, as previously described. At 12, 24, 48 and $72 \mathrm{~h}$ after injection the mice were scanned using a single head rotating scintillation camera of SPECT. When the tumor was clearly visible, SPECT/CT image fusion was performed in nude mice (high energy collimator, matrix 256x256, with a peak at $364 \mathrm{keV}$, and an acquisition time for each frame of $15 \mathrm{~min}$ ).

Statistical methods. All experimental data were analyzed using the statistical software SPSS 22.0 (IBM Corp., Armonk, NY, USA) and graphically expressed as the mean \pm standard deviation (mean \pm SD). A Student's t-test was used for the comparison of two sample means, the mean of variance was compared by single factor analysis, and the quantitative data were analyzed using the $\chi^{2}$ test. A value of $\mathrm{P}<0.05$ was considered significant.

\section{Results}

Production and purification of $s c F v$. Analysis of phage antibody specificity by ELISA revealed that of the 12 monoclonal phages, eight reacted positively to ARO cells, giving a positive rate of $66.7 \%$. Phage-infected $E$. coli TG1 expressed the soluble protein. The results of the purification of the soluble antibody on the Sephadex G25M column and the peak value of 15-21 represents the purified soluble antibody scFv.15-21. The tubes with the highest readings at A280 nm were considered to be the purified expression of soluble scFv. 


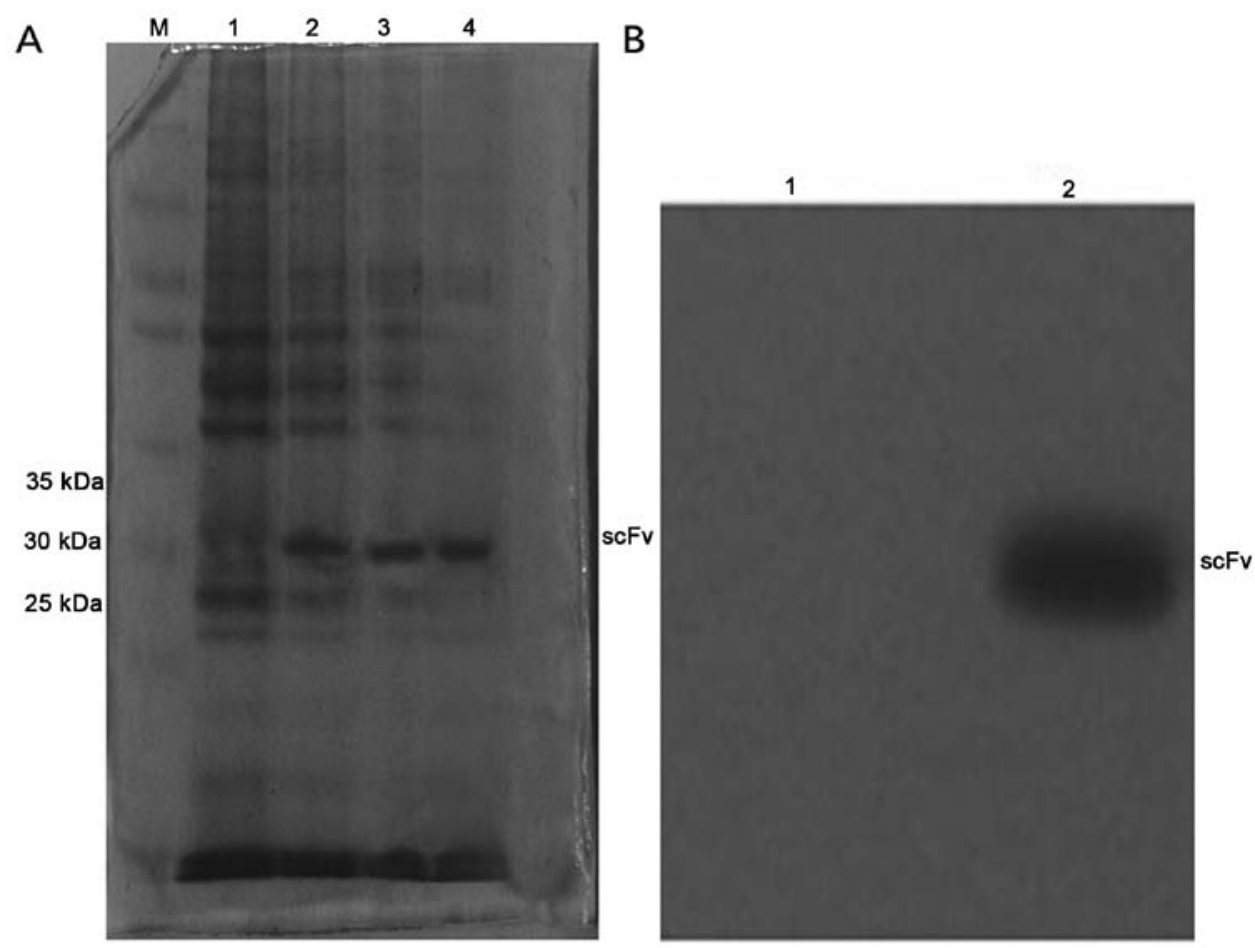

Figure 1. (A) SDS-PAGE analysis of scFv expression. M, marker; lane 1, E. coli HB2151; lane 2, $4 \mathrm{~h}$ of purification of scFv induced by IPTG; lane 3, $6 \mathrm{~h}$ of purification of scFv induced by IPTG; lane 4, the purified antibody scFv. (B) Western blotting detection of purified scFv; lane 1, E. coli HB2151; lane 2, the purified antibody scFv. scFV, single-chain variable fragment; IPTG, isopropyl- $\beta$-D-thiogalactoside.

Table I. Detection of scFv.

A, Detection of scFv

\begin{tabular}{|c|c|c|c|c|c|}
\hline & \multirow[b]{2}{*}{ Group } & \multirow{2}{*}{$\begin{array}{l}\text { Deviation } \\
\text { from } \\
\text { average }\end{array}$} & \multirow[b]{2}{*}{$\begin{array}{l}\text { Standard } \\
\text { error }\end{array}$} & \multicolumn{2}{|c|}{$95 \% \mathrm{CI}$} \\
\hline & & & & $\begin{array}{l}\text { Lower } \\
\text { limit }\end{array}$ & $\begin{array}{l}\text { Upper } \\
\text { limit }\end{array}$ \\
\hline \multirow[t]{3}{*}{ ARO } & HepG2 & 0.191 & $0.0159^{\mathrm{a}}$ & 0.155 & 0.227 \\
\hline & PBS & 0.318 & $0.0159^{\mathrm{a}}$ & 0.281 & 0.355 \\
\hline & $\mathrm{TT}$ & 0.242 & $0.0159^{\mathrm{a}}$ & 0.205 & 0.279 \\
\hline
\end{tabular}

$\mathrm{B}$, Detection of $\mathrm{scFv}$

\begin{tabular}{lccc}
\hline Group & Average & No. & $\begin{array}{c}\text { Standard } \\
\text { deviation }\end{array}$ \\
\hline ARO & 0.369 & 3 & 0.029 \\
HepG2 & 0.178 & 3 & 0.015 \\
PBS & 0.051 & 3 & 0.004 \\
TT & 0.127 & 3 & 0.021 \\
Total & 0.181 & 12 & 0.124 \\
\hline
\end{tabular}

${ }^{\mathrm{a}} \mathrm{P}<0.05$. $\mathrm{scFv}$, single-chain variable fragment; $\mathrm{CI}$, confidence interval; PBS, phosphate-buffered saline.

SDS-PAGE and western blotting. The scFv induced by IPTG at 4 and $6 \mathrm{~h}$ was run on SDS-PAGE followed by Coomassie brilliant blue staining, with uninduced E. coli HB2151 used as

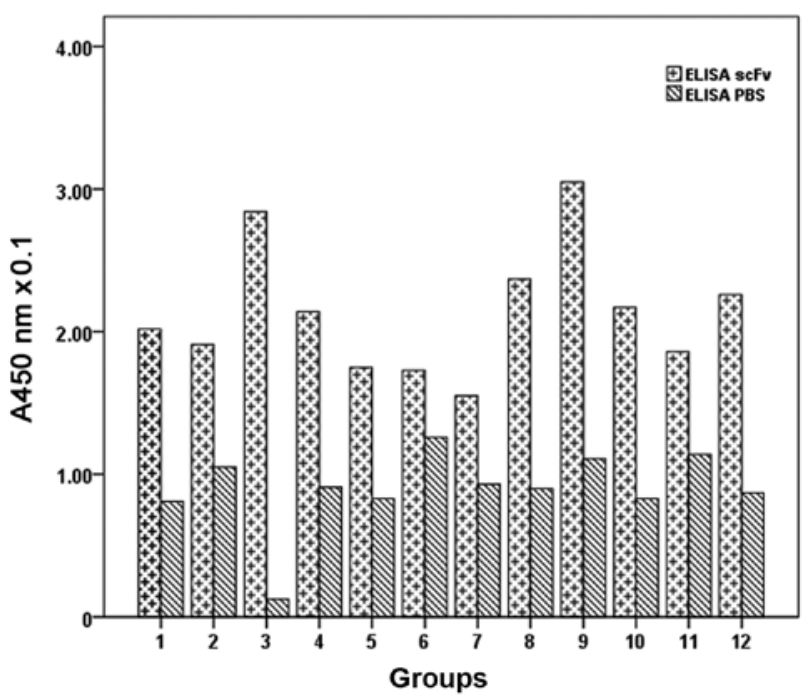

Figure 2. Detection of the binding activity of scFv and ARO cells. ELISA, enzyme-linked immunosorbent assay; PBS, phosphate-buffered saline; scFv, single-chain variable fragment.

the control. Western blotting of the purified scFv revealed that $\mathrm{scFv}$ has a relative molecular mass of $\sim 29 \mathrm{kDa}$ (Fig. 1).

ELISA detection of phage antibody. ELISA results showed that the absorbance of ARO cells at $450 \mathrm{~nm}$ was $0.37 \pm 0.03$, while the absorbance of hepatocarcinoma cells was $0.18 \pm 0.01$, that of TT cells was $0.13 \pm 0.02$, and the PBS control group was $0.05 \pm 0.00$. Analysis of variance showed that the differences were statistically significant $(\mathrm{P}<0.05)$, and confirmed that the specificity of ARO cells was higher than the other cells (Table I; Fig. 2). 

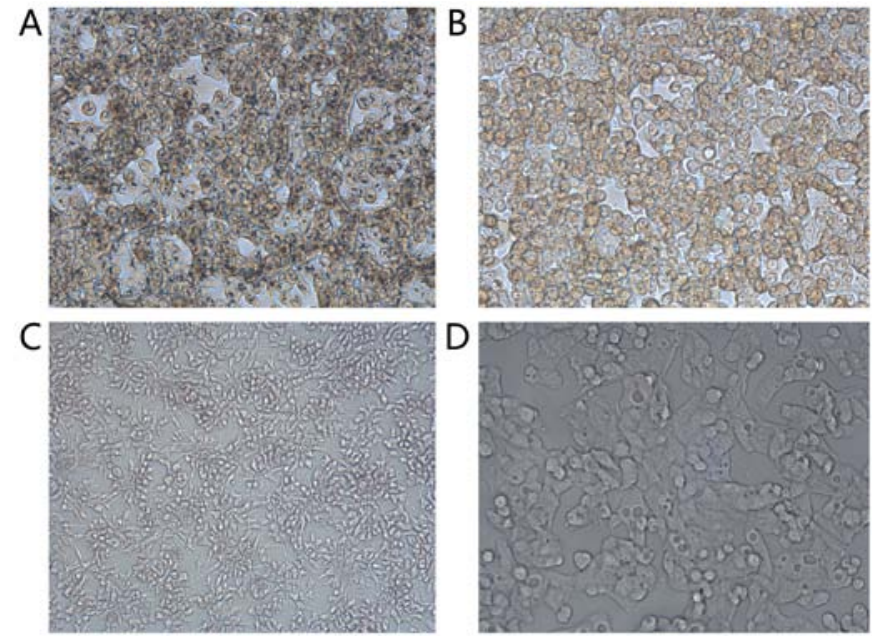

Figure 3. The specific detection of the soluble antibody under light microscopy (magnification, $\mathrm{x} 200$ ). (A) ARO cells, positive. (B) ARO cells, negative. (C) TT cells, negative. (D) HepG2 cells, negative.
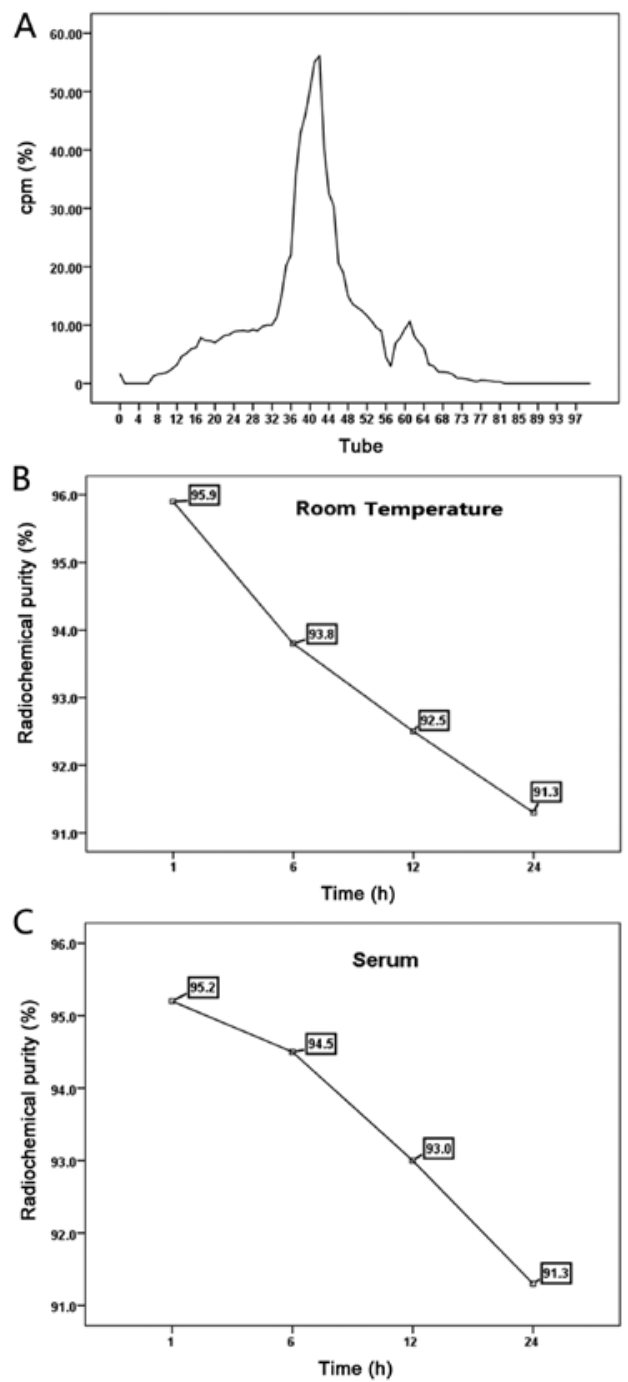

Figure 4. (A) Purification of ${ }^{131} \mathrm{I}-\mathrm{scFv}$. The assessment of the radioactivity of 100 tubes revealed two emission bands, a first emission peak was located in tubes 34-49 and the second radioactive peak was found in tubes 57-64 (B) The room temperature stability test of ${ }^{131} \mathrm{I}-\mathrm{scFv}$. The radiochemical purity was $95.9,93.8,92.5$ and $91.3 \%$ at $1,6,12$ and $24 \mathrm{~h}$, respectively. (C) The serum stability test of ${ }^{131} \mathrm{I}-\mathrm{scFv}$. The radiochemical purity was $95.2,94.5,93.0$ and $91.3 \%$ at $1,6,12$ and $24 \mathrm{~h}$, respectively. scFv, single-chain variable fragment.
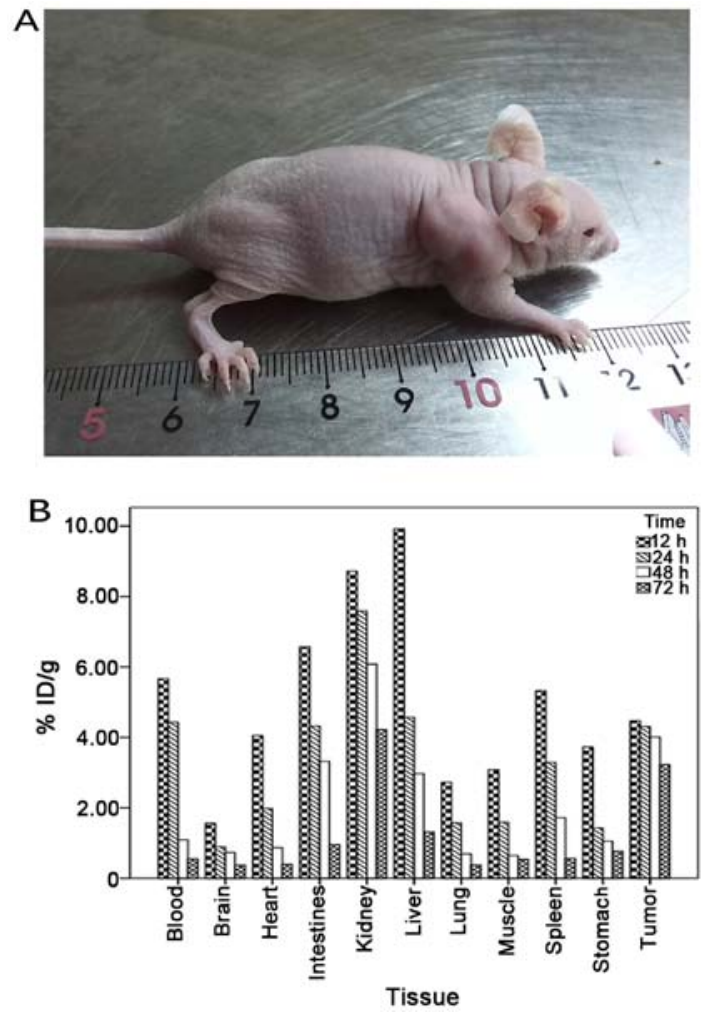

Figure 5. (A) Human ATC-bearing nude mouse. The tumor volume was increased to $>1 \mathrm{~cm}^{3}$. (B) Distribution of ${ }^{131} \mathrm{I}-\mathrm{scFV}$ in tumor-bearing nude mice. The concentration of radioactivity of the tumor tissues, liver, kidney, intestine and blood were all high in the early stage, but as time increased, in other tissues except for tumor tissues it was significantly decreased. ATC, anaplastic thyroid carcinoma.

Light microscopy results also showed that scFv had a high specificity for ARO cells (Fig. 3).

Radiolabeling, purification and radiochemical purity test. The $\mathrm{scFv}$ was successfully labeled with ${ }^{131} \mathrm{I}$ using the chloramine T method, and then purified using a Sephadex G25M column. Eluent fractions were collected in 100 tubes of ${ }^{131} \mathrm{I}-\mathrm{scFv}$, and by evaluating the radioactivity in each tube, two emission peaks were revealed, the first located in tubes 34-49, while the second radioactive peak was found in tubes 57-64. The eluent of the first radiation peak was collected, purified and labeled ${ }^{131} \mathrm{I}-\mathrm{scFv}$. The labeling rate was found to be $91.64 \%$ and the radiochemical purity was $93.3 \pm 0.32 \%$. Purified ${ }^{131} \mathrm{I}-\mathrm{scFv}$ was maintained at room temperature for $1,6,12$ or $24 \mathrm{~h}$ before its addition to fresh human serum and incubation at $37^{\circ} \mathrm{C}$ for 1 , 6,12 or $24 \mathrm{~h}$. The radiochemical purity was assessed and the stability of the ${ }^{131} \mathrm{I}-\mathrm{scFv}$ after storage at room temperature and in serum was analyzed at the different time-points (Fig. 4).

Animal models and biodistribution. Four weeks after injecting ARO cells, an ATC-bearing nude mouse model was successfully constructed (Fig. 5). Examination of the in vivo distribution of ${ }^{131} \mathrm{I}-\mathrm{scFv}$ in tumor-bearing nude mice revealed that ${ }^{131} \mathrm{I}-\mathrm{scFv}$ was mainly distributed in tumor tissue and in liver, kidney, spleen, heart, lung, stomach, intestine, brain, muscle and blood. The concentrations of radioactivity in the tumor tissues, liver, kidney, intestine and blood were all high after injection, but with increasing time, the levels of 
Table II. Distribution of ${ }^{131} \mathrm{I}-\mathrm{scFv}$ in tumor-bearing nude mice.

\begin{tabular}{lcccc}
\hline Tissue & $12 \mathrm{~h}$ & $24 \mathrm{~h}$ & $48 \mathrm{~h}$ & $72 \mathrm{~h}$ \\
\hline Tumor & $4.47 \pm 0.56$ & $4.31 \pm 0.72$ & $4.01 \pm 0.66$ & $3.23 \pm 0.09$ \\
Liver & $9.92 \pm 0.31$ & $4.57 \pm 0.23$ & $2.97 \pm 0.69$ & $1.32 \pm 0.33$ \\
Kidney & $8.72 \pm 0.11$ & $7.59 \pm 0.47$ & $6.08 \pm 0.72$ & $4.23 \pm 0.91$ \\
Spleen & $5.32 \pm 0.57$ & $3.29 \pm 0.58$ & $1.72 \pm 0.37$ & $0.56 \pm 0.20$ \\
Lung & $2.73 \pm 0.11$ & $1.57 \pm 0.52$ & $0.69 \pm 0.76$ & $0.38 \pm 0.55$ \\
Stomach & $3.73 \pm 0.98$ & $1.43 \pm 0.24$ & $1.05 \pm 0.63$ & $0.77 \pm 0.36$ \\
Intestine & $6.57 \pm 0.72$ & $4.32 \pm 0.64$ & $3.32 \pm 0.53$ & $0.96 \pm 0.32$ \\
Brain & $1.56 \pm 0.11$ & $0.89 \pm 0.12$ & $0.73 \pm 0.26$ & $0.87 \pm 0.22$ \\
Heart & $4.05 \pm 0.07$ & $1.98 \pm 0.20$ & $0.65 \pm 0.32$ & $0.40 \pm 0.02$ \\
Muscle & $3.08 \pm 0.28$ & $1.59 \pm 0.39$ & $1.09 \pm 0.12$ & $0.54 \pm 0.65$ \\
Blood & $5.67 \pm 0.89$ & $4.43 \pm 0.25$ & & $0.55 \pm 0.07$ \\
Ratio & & & $5.49 \pm 0.31$ & \\
Tumor/brain & $2.86 \pm 0.33$ & $4.84 \pm 0.60$ & $6.16 \pm 0.02$ & $3.67 \pm 0.62$ \\
Tumor/muscle & $1.45 \pm 0.22$ & $2.71 \pm 0.25$ & $0.97 \pm 0.32$ & $5.98 \pm 0.01$ \\
Tumor/blood & $0.18 \pm 0.03$ & & & $5.87 \pm 0.11$ \\
\hline
\end{tabular}

A

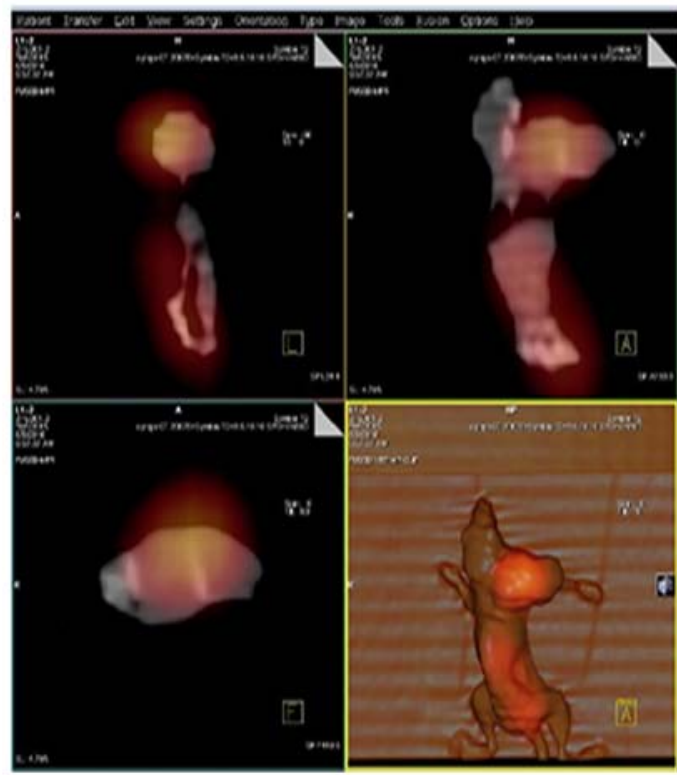

B

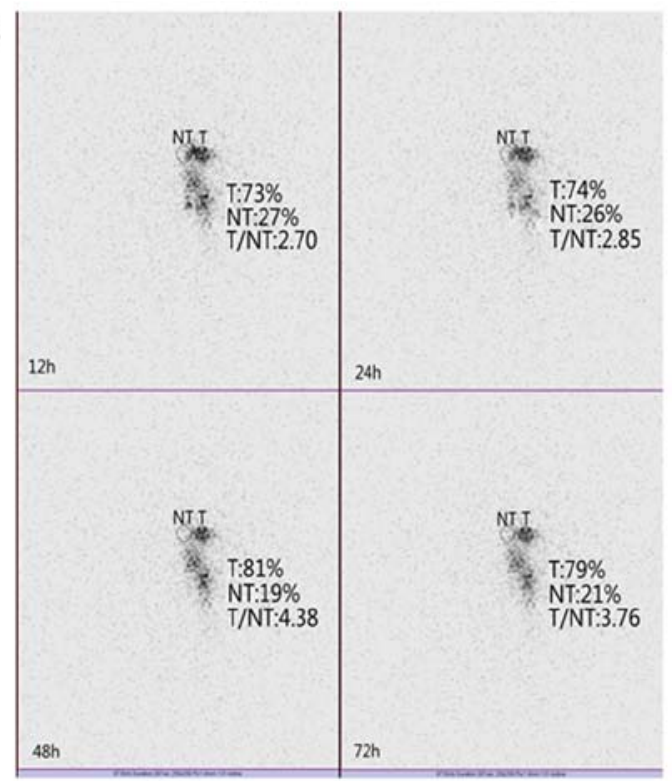

Figure 6. SPECT/CT fusion imaging and static SPECT imaging. (A) SPECT/CT fusion imaging and simulated imaging of a tumor-bearing mouse at $48 \mathrm{~h}$ after the injection of ${ }^{131} \mathrm{I}-\mathrm{scFv}$ into the tail vein. (B) SPECT imaging of a tumor-bearing mouse after the caudal vein injection of ${ }^{131} \mathrm{I}$-scFv. scFv, single-chain variable fragment; SPECT/CT, single photon emission computed-tomography/computed-tomography.

radioactivity in other tissues were decreased while those in the tumor tissues remained high (Table II; Fig. 5). ${ }^{131} \mathrm{I}-\mathrm{scF}$ revealed a long residence time and a slow rate of clearance in tumor tissue. In addition, the ratio of radioactivity of tumor:blood and tumor:muscle increased with time, reaching a peak at $48 \mathrm{~h}$.

SPECT/CT RII in tumor-bearing nude mice. The SPECT/CT imaging results revealed that tumor tissue in tumor-bearing nude mice was still clearly visible at $48 \mathrm{~h}$, and the highest target/non-target (T/NT) value was 4.38 . The concentrations of radioactivity in other parts of the body were decreased (Fig. 6).

\section{Discussion}

Related studies have shown that the molecular pathogenesis of ATC involves a series of gene mutations, chiefly of BRAF, RAS, catenin (cadherin-associated protein) $\beta 1$, PIK3CA, AXIN1, TP53, PTEN and APC, and that chromosomal abnormalities are common (11). Mutations in the p53 tumor-suppressor gene results in the production of inactive $\mathrm{p} 53$ proteins that have been found in most cases of ATC, but not in other thyroid tumors (12). Mutations in the $\beta$-chain protein gene occur in as many as $65 \%$ of ATC cases (13). The evidence for a high degree of differentiation was provided by a study of undifferentiated carcinoma and concomitant BRAF mutations 
in the region of the p53 mutation in the second step $(14,15)$. Due to the fact that ATC gene therapy is currently still in the early stages, most research is still in the exploratory stage. Induction differentiation therapy has better effects in vitro, but currently there are no large-scale clinical trials, pending further research. Coupling of a radioactive nuclide to an orientation-specific antibody creates a radio-immunoassay drug treatment method suitable for in vivo use. Known as radioimmunotherapy (RIT), it has provided a novel approach to ATC diagnosis and treatment $(16,17)$. To date, numerous studies (18) have achieved promising RII results with the use of radioactive nuclide-labeled antibodies.

Recently, as phage-display technology has matured, our research group used this technique to establish an ATC phage antibody library and screen antibodies for ATC specificity. The biological characteristics of the antibodies were analyzed by ELISA, SDS-PAGE and western blotting. Results identified an antibody which exhibited specificity to ARO cells. Then, the purified $\mathrm{ScFV}$ was labeled with ${ }^{131} \mathrm{I}$, the ARO cells were injected into nude mice in vivo, and a radioimmunoassay was successfully achieved. Use of the ${ }^{131}$ I-labeled polypeptide was feasible in the present study. The labeling rate of ${ }^{131} \mathrm{I}-\mathrm{scFv}$ was $91.64 \%$, the radio-chemical purity of purified ${ }^{131} \mathrm{I}-\mathrm{scFv}$ was $93.3 \pm 0.32 \%$ and the radiochemical purity of ${ }^{131} \mathrm{I}-\mathrm{scFv}$ which was stored at $37^{\circ} \mathrm{C}$ in human blood serum at $24 \mathrm{~h}$ was $91.9 \%$. These results demonstrated that ${ }^{131} \mathrm{I}-\mathrm{scFv}$ had good stability in vitro, and met the requirements of in vivo experimental study on peptides (19). SPECT imaging can directly observe the dynamic changes in the in vivo distribution of the agents imaged. Results of ${ }^{131} \mathrm{I}-\mathrm{scFv}$ polypeptide imaging showed that, in nude mice xenografted with ARO cells, dynamic changes in distribution of the imaging agent in vivo can be directly observed using SPECT imaging, which is closer to clinical practice. Concentrations of radioactivity were not found in the thyroid at any time after injection mainly since the labeled compound targets the tumor vasculature with high affinity and specificity and is stable without iodothyronine. This is consistent with the results from the asssessment of the in vitro stability of ${ }^{131} \mathrm{I}-\mathrm{scF}$. SPECT imaging using ${ }^{131} \mathrm{I}-\mathrm{scFv}$ revealed a higher tumor uptake in the mice bearing ARO cells. The experimental results revealed that in tumor-bearing nude mice at $48 \mathrm{~h}$ after intravenous injection of ${ }^{131} \mathrm{I}-\mathrm{scFv}$, the tumor imaging was clear. Concomitantly, the T/NT reached the highest value of 4.38, suggesting that the antibody bound specifically to ARO cells. The final objective of the imaging was to explore methods of treatment which could be used to target and destroy tumor cells by binding to the specific tumor antigen. ${ }^{131} \mathrm{I}$ is a good imaging agent which is currently used in the clinical diagnosis and treatment of thyroid disease (20). If combined with the purified $\mathrm{scFv}$, as used for imaging of tumor-bearing nude mice, it could provide a new way of diagnosing and treating ATC. In future our research may continue to focus on ATC treatment with ${ }^{131} \mathrm{I}-\mathrm{scFv}$, to confirm the specific effect of ${ }^{131} \mathrm{I}-\mathrm{scFv}$ in killing tumor cells.

There are some limitations to this experimental study. Traditional screening methods were used and ways to increase antibody concentration to avoid the loss of the antibody under screening conditions (21) may need to be explored and further optimized in later experiments. IPTG, used in this experiment, is toxic; various studies (22) have shown that lactose can also be utilized in the induction process and is safe and non-toxic, thus we may consider using lactose induction in our future experiments. In the early stage of imaging, blood, liver and kidney tissue all exhibited a high concentration of radioactivity, but with time, the concentration of radiation in these organs significantly decreased. The high concentration in the kidney may be related to the excretion of the labeled antibodies. The high concentration in the liver may due to reticuloendothelial cells non-specifically taking up ${ }^{131} \mathrm{I}-\mathrm{scFv}$, or there may be some fragment crystallizable ( $\mathrm{Fc}$ ) receptors. Consequently, focusing on improving the process, for example, how to carry out chemical modifications when designing $\mathrm{scFv}$ to decrease the radioactivity uptake of non-tumor tissue, and to make $\mathrm{scFv}$ stay specifically in the tumor tissue, is warranted.

In conclusion, human single-chain variable fragment antibodies against ATC were successfully generated. ${ }^{131} \mathrm{I}-\mathrm{scFv}$ was successfully prepared, and the imaging of ${ }^{131} \mathrm{I}-\mathrm{scFv}$ in a nude mouse model at $48 \mathrm{~h}$ after injection of tumor cells clearly showed it specifically localized in the tumor tissue. In the future we may continue to investigate the potential of this construct in anticancer therapy.

\section{Acknowledgements}

The authors gratefully acknowledge the assistance of the Department of Nuclear Medicine, First Affiliated Hospital of Chongqing Medical University, Institute of Life Sciences and Animal Experimental Center of Chongqing Medical University. The present study was funded by the National Natural Science Foundation of China (no. 81071171), the Project of Science and Technology plan of Chongqing (CSCT2013JCYJA10072), and supported by the National Key Clinical Specialties Construction Program of China [National Health Office of medical letter (2013) no. 544].

\section{References}

1. Amodeo C, Caglià P, Gandolfo L, Veroux M, Donati M and Immè A: Undifferentiated carcinoma of the thyroid. Tumori 89 (Suppl 4): S205-S206, 2003 (In Italian).

2. Denaro N, Nigro CL, Russi EG and Merlano MC: The role of chemotherapy and latest emerging target therapies in anaplastic thyroid cancer. Onco Targets Ther 9: 1231-1241, 2013.

3. Kihara M, Miyauchi A, Yamauchi A and Yokomise H: Prognostic factors of anaplastic thyroid carcinoma. Surg Today 34: 394-398, 2004.

4. Xia J, Bi H, Yao Q, Qu S and Zong Y: Construction of human ScF phage display library against ovarian tumor. JJ Huazhong Univ Sci Technolog Med Sci 26: 497-499, 2006.

5. McFadden DG, Vernon A, Santiago PM, Martinez-McFaline R, Bhutkar A, Crowley DM, McMahon M, Sadow PM and Jacks T: p53 constrains progression to anaplastic thyroid carcinoma in a Braf-mutant mouse model of papillary thyroid cancer. Proc Natl Acad Sci USA 111: E1600-E1609, 2014.

6. Luo Y, Pang H, Li S, Cao H, Peng Z, Fan C and Li S: Production and radioimmunoimaging of novel fully human phage display recombinant antibodies and growth inhibition of lung adenocarcinoma cell line overexpressing Prx I. Cancer Biol Ther 8: 1369-1377, 2009.

7. Qiong L, Hua P, Xi J, Li W and Lu X: Medullary thyroid carcinoma like humanized phage single chain antibody screening and identification. Chongqing Yike Daxue Xuebao 9: 12-16, 2015

8. Duan D, Li SL, Zhu YQ and Wang SB: Effects of radioimmunoimaging with ${ }^{99} \mathrm{Tc}^{\mathrm{m}}$-EGFR-McAb or ${ }^{99} \mathrm{Tc}^{\mathrm{m}}-\mathrm{CD} 44-\mathrm{McAb}$ or combined application of both on nude mice bearing human lung adenocarcinoma. J Third Mil Med Univ 31: 1287-1280, 2009. 
9. Zhao WS, Luo Y,Li BY,Zhou HJ and Zhang T: Anti-ABCG2 scFy antibody of lung adenocarcinoma increases chemosensitivity and induces apoptosis through the activation of mitochondrial pathway. Am J Cancer Res 6: 1026-1039, 2016.

10. Xi J, Hua P, Sen Z, Qiong L and Li W: Thyroid without differentiation carcinoma of human $\mathrm{scFv}$ antibody library construction and screening. J Immunol 31: 692-696, 2015.

11. Smallridge RC, Marlow LA and Copland JA: Anaplastic thyroid cancer: Molecular pathogenesis and emerging therapies. Endocr Relat Cancer 16: 17-44, 2009.

12. Fagin JA, Matsuo K, Karmakar A, Chen DL, Tang SH and Koeffler HP: High prevalence of mutations of the p53 gene in poorly differentiated human thyroid carcinomas. J Clin Invest 91: $179-184,1993$.

13. Garcia-Rostan G, Camp RL, Herrero A, Carcangiu ML, Rimm DL and Tallini G: $\beta$-catenin dysregulation in thyroid neoplasms: Down-regulation, aberrant nuclear expression, and CTNNB1 exon 3 mutations are markers for aggressive tumor phenotypes and poor prognosis. Am J Pathol 158: 987-996, 2001.

14. Nikiforova MN, Kimura ET, Gandhi M, Biddinger PW, Knauf JA, Basolo F, Zhu Z, Giannini R, Salvatore G, Fusco A, et al: BRAF mutations in thyroid tumors are restricted to papillary carcinomas and anaplastic or poorly differentiated carcinomas arising from papillary carcinomas. J Clin Endocrinol Metab 88: 5399-5404, 2003.

15. Quiros RM, Ding HG, Gattuso P, Prinz RA and Xu X: Evidence that one subset of anaplastic thyroid carcinomas are derived from papillary carcinomas due to $B R A F$ and p53 mutations. Cancer 103: 2261-2268, 2005.

16. Gui PL and Cheng MZ: Tumor radioimmunoimaging and treatment of a predetermined bit technology. Foreign Medical Oncology 25: 26-29, 1998.
17. Vezzosi D, Bennet A, Caron P. Recent advance in treatment of medullary thyroid carcinoma. Ann Endrocrinol 68: 147-153, 2007.

18. Rubello D, Rampin L, Nanni C, Banti E, Ferdeghini M, Fanti S, Al-Nahhas A and Gross MD: The role of ${ }^{18} \mathrm{~F}-\mathrm{FDG}$ PET/CT in detecting metastatic deposits of recurrent medullary thyroid carcinoma: A prospective study. Eur J Surg Oncol 34: 581-586, 2008.

19. Subedi GP, Satoh T, Hanashima S, Ikeda A, Nakada H, Sato R, Mizuno M, Yuasa N, Fujita-Yamaguchi Y and Yamaguchi Y: Overproduction of anti-Tn antibody MLS128 single-chain Fv fragment in Escherichia coli cytoplasm using a novel pCold-PDI vector. Protein Expr Purif 82: 197-204, 2012.

20. Staelens S, Desmet J, Ngo TH, Vauterin S, Pareyn I, Barbeaux P, Van Rompaey I, Stassen JM, Deckmyn H and Vanhoorelbeke K: Humanization by variable domain resurfacing and grafting on a human $\mathrm{IgG}_{4}$, using a new approach for determination of non-human like surface accessible framework residues based on homology modelling of variable domains. Mol Immunol 43: 1243-1257, 2006.

21. Vanden Borre P, McFadden DG, Gunda V, Sadow PM, Varmeh S, Bernasconi M, Jacks T and Parangi S: The next generation of orthotopic thyroid cancer models: Immunocompetent orthotopic mouse models of BRAF ${ }^{\mathrm{V} 600 \mathrm{E}}$-positive papillary and anaplastic thyroid carcinoma. Thyroid 24: 705-714, 2014.

22. Yang J, Yu C, Liao L and Liao H: Expression of human insulin like growth factor-1 in Escherichia coli induced by lactose. Strait Med 22: 248-252, 2010. 